\title{
PASOLINI TRADUTOR DA ENEIDA DE VIRGÍLIO
}

\author{
Pedro Falleiros Heise ${ }^{1}$ \\ ${ }^{1}$ Universidade Federal de Santa Catarina, Florianópolis, Santa Catarina, Brasil
}

\begin{abstract}
Resumo: Além de poeta, cineasta, dramaturgo e crítico da cultura, Pasolini foi também tradutor. Traduziu principalmente poesia lírica, dramática e épica, de várias línguas diferentes. Dentre suas traduções destaca-se o longo trecho da abertura da Eneida. Apresentamos neste artigo alguns aspectos da discussão que Pasolini nos oferece sobre tradução, assim como uma análise de algumas de suas escolhas ao traduzir os versos da obra-prima de Virgílio.
\end{abstract}

Palavras-chave: Pasolini; Virgílio; Eneida; Tradução

\section{PASOLINI TRANSLATOR OF VIRGIL'S AENEID}

\begin{abstract}
Pasolini was not only a poet, film-maker, playwright and culture critic, but also a translator. He translated mainly lyric, dramatic and epic poetry from several different languages. Among his translations stands out the long opening section of the Aeneid. This paper intends to present some aspects of the discussion that Pasolini offers us about translation, as well as an analysis of some of his choices to translate those verses of Virgil's masterpiece.
\end{abstract}

Keywords: Pasolini; Virgil; Aeneid; Translation

Nas várias manifestações artísticas empreendidas por Pasolini, deve-se incluir a tradução de poesia. Trata-se de ramo da produção pasoliniana pouco explorado, que conta com traduções que ainda hoje são inéditas, ou seja, nem sequer foram publicadas. Algumas destas traduções vieram à luz nos anos 40 em revistas friulanas, 
outras foram inseridas na coletânea organizada pelo também poeta Attilio Bertolucci (Poesia straniera del Novecento, 1958).

A língua da qual Pasolini mais traduziu é o francês, mas há também línguas que conhecia menos, como o espanhol e o inglês. Para ele não houve problemas em traduzir poetas de línguas que de fato nem conhecia, como o alemão e o japonês, valendo-se de outras traduções italianas para realizar as suas próprias. A "disperata vitalità" do poeta se mostra aqui também: são nada mais nada menos que 10 línguas diferentes das quais traduziu, e não só para o italiano, mas também para o romanesco e para o friulano, língua de seu primeiro livro de poesias (Poesie a Casarsa, 1942) e de sua primeira antologia poética, intitulada La meglio gioventù (1954).

A escolha de traduzir poesias em friulano faz parte de um projeto de política cultural, que vai, basicamente, de 1945 a 1954, cujo intuito era dar dignidade literária ao friulano, demonstrando sua capacidade de se medir com os grandes textos da poesia em outras línguas. Em 1947, no artigo "Da língua [italiana] ao friulano", Pasolini escreve (Saggi sulla letteratura e sull'arte 282):

O friulano precisa de traduções, sendo este o passo mais probatório para a sua promoção a língua. É verdade que para nós o friulano é a priori uma língua, à parte as considerações glotológicas (um retorno deliberado a Ascoli) e à parte o esforço consciente de usá-lo em condições de paridade, se não de igualdade com as grandes línguas romances; todavia uma experiência como a do tradutor viria a constituir um terceiro fato, se não muito profundo, pelo menos peremptório. ${ }^{1}$

\footnotetext{
1 "Il friulano ha bisogno di traduzioni essendo questo il passo più probatorio per una sua promozione a lingua. È vero che per noi il friulano è aprioristicamente lingua, a parte le considerazioni glottologiche (un deliberato ritorno all'Ascoli) e a parte lo sforzo cosciente di usarlo in condizioni di parità se non di uguaglianza con le grandi lingue romanze; tuttavia una prova come quella del traduttore verrebbe a costituire un terzo fatto, se non molto profondo, almeno perentório". Todas as traduções são de nossa lavra, salvo indicação contrária.
}

Cad. Trad., Florianópolis, v. 39, n 3, p. 209-229, set-dez, 2019. 
Um ano antes deste artigo, em 1946, Pasolini havia ajudado a organizar uma publicação em dois volumes de tradução de poesias estrangeiras contemporâneas: um volume ficaria a cargo de Nico Naldini, com poetas espanhóis, enquanto no outro Pasolini apresentaria La zoja ("A guirlanda"), com o subtítulo "poesiis forestis di vuei" ("poesias estrangeiras de hoje"). Estas traduções faziam parte do projeto político-linguístico de Pasolini mencionado há pouco.

No texto "Apresentação do último número de Stroligut", a revista da Academiuta di lenga furlana, dirigida por Pasolini, o poeta explica a ideia destas traduções (Saggi sulla letteratura e sull'arte 162 e 164, grifos nossos):

E como justificar diante de um leitor desprovido ou não informado, o segundo número regular de uma antologia poética que assumiu o preciso programa de enxertar um friulano desautorizado pelos vernáculos no tronco de uma tradição em língua [italiana]? [...] De resto, a fidelidade literária era naturalmente o que menos me importava; mas não tanto porque eu fosse obrigado a isso por causa da inconciliabilidade, justamente na letra, entre duas línguas, quanto por uma necessidade de reconstruir, e não de traduzir, em friulano. ${ }^{2}$

Será importante reter a ideia do poeta em não traduzir "fielmente" o texto de origem, pois o que lhe interessava era elevar o dialeto friulano para a classificação de língua. Passado este momento, com a sua filiação ao Partido Comunista em 1948, Pasolini não se aventurará mais com tanto afinco nas traduções para o friulano; mesmo as traduções para o italiano serão cada

2 "E come giustificare davanti a un lettore sprovveduto o non informato, il secondo numero regolare di un'antologia poetica che si è assunta il preciso programma di innestare un friulano esautorato dai vernacoli nel tronco di una tradizione di lingua? [...] Del resto la fedeltà letterale era naturalmente ciò che mi importava di meno; ma non tanto perché ne fossi costretto dall'inconciliabilità, appunto nella lettera, delle due lingue, quanto per un bisogno di ricostruire, e non di tradurre, in friulano".

Cad. Trad., Florianópolis, v. 39, nº 3, p. 209-229, set-dez, 2019. 
vez mais esporádicas, geralmente relacionadas a "encomendas" precisas, conforme veremos.

Como já foi dito, a maior parte destas traduções é inédita. No volume mondadoriano das suas poesias, Tutte le poesie, o mais completo até o presente, encontramos traduções de Safo, dos Carmina burana, de Baudelaire, Verlaine, Rimbaud, Jules Laforgue, Apollinaire, Juan Ramón Jimenez, Pedro Salinas, García Lorca, T. S. Eliot, Hölderlin, Georg Trakl, Sei Shonagon, Shivoi Uko, uns traduzidos para o friulano, outros para o italiano, alguns meio friulano meio italiano, como o poema Enfance de Rimbaud, cuja tradução começa em italiano e acaba em friulano. Além destes, Pasolini traduziu também poetas italianos para o friulano, poesias de Pascoli, Ungaretti e Quasimodo.

Marcos nas suas traduções são a trilogia de Ésquilo, Oresteia, e a comédia de Plauto, Miles gloriosus, ambas realizadas a pedido do ator Vittorio Gassman e do diretor Luciano Lucignani. As reações por parte da crítica quanto àquela variaram entre resultado esplêndido e um Ésquilo distorcido. Recentemente, Federico Condello, no artigo "Su Pasolini traduttore classico: rilievi sparsi, tra fatto e legende", afirma que a ideia de escândalo acerca da tradução da Oresteia teria sido forjada pelos "apologetas" de Pasolini, quando não pelo próprio poeta, que era, na visão de Condello, “contraditório" (Condello 8).

Em seguida, o estudioso passa a uma crítica de cunho estritamente filológico, através da "atomização" (Condello 10) de alguns versos que analisa, e assistimos, mais uma vez, ao exame detento apenas nos valores semânticos e lexicais do original que Pasolini ou não teria traduzido ou teria traduzido de forma equivocada. Ora, o que o estudioso não realiza, ao menos neste artigo, é a inserção destas traduções no contexto da obra (toda) de Pasolini. Por exemplo, ao analisar os seis primeiros versos da tradução da Eneida, Condello afirma: "ele fixa desde o incipit o usual método de tradução por palavras-slogan, com programática e sistemática redução do hipotexto a repertório lexical (ou semântico) fechado" 
$(13)^{3}$. Condello não cogitou, ao que parece, que essas "palavras -slogan" seriam justamente aquele grupo de vocábulos que mais recorrem num dado poeta, que fornecem as marcas de sua poética. O que não ocorreu ao estudioso, enfim, foi analisar as traduções de Pasolini enquanto obras de um tradutor-poeta, ou melhor, de um poeta-tradutor. É como se criticasse a famosa tradução do hemistíquio da bucólica virgiliana feita por Vinícius de Moraes na poesia Pátria minha por estar "errada":
um libertas quae sera tamen
que um dia traduzi num exame escrito:
"liberta que serás também"
e repito!

Vemos que Vinícius tem consciência do equívoco de sua tradução, mas mesmo assim não o corrige ("e repito!"), pois quadra bem na sua poética, que em dados momentos privilegia o ideal de liberdade. Analogamente, as traduções de Pasolini fazem parte da sua poética, não são traduções que nós, professores e tradutores profissionais, fazemos de costume ${ }^{4}$. São traduções de poetas ${ }^{5}$. É

3 “[...] egli imposta fin dall'incipit il consueto metodo di traduzione per paroleslogan, con programmatica e sistematica riduzione dell'ipotesto a repertorio lessicale (o semantico) chiuso".

${ }^{4}$ A este respeito, pode ser útil lembrar a distinção que Georges Mounin faz entre a tradução do professor e a do poeta (Mounin 149): “A tradução do professor pode ser fraca; a do poeta pode estar errada. Todavia, o poeta mantém um seu privilégio porque tem mais probabilidade do que outros tradutores de possuir a capacidade de compreensão total ou quase total de um texto, sem a qual se conhece somente a língua".

${ }^{5}$ Outro exemplo ilustre são as Metamorfoses de Ovídio na tradução de Bocage. Cf. introdução de João Angelo Oliva Neto, que comenta (Bocage 30-31): "Não existem no original 'triste' nem 'incauto', inchaços, mas Bocage compensa cortando o 'sua origem', substituindo-o pelo mínimo 'quem é', que associado ao literal 'conhecer', de sabor délfico ('conhece-te a ti mesmo’), dá à passagem efeito de síntese patética e dramática. [...] Mas o princípio geral [...] que nos parece 
o que afirma, por exemplo, Paolo Lago no artigo "Un logos antiaccademico: Pasolini traduttore dell'Eneide": "há pontos em que o tradutor traduz o texto latino com palavras ou nexos que fazem parte do seu universo poético" (Lago 25) .

O fato é que as traduções dos antigos feitas por Pasolini suscitaram elogios e críticas, algumas das quais reunidas e contextualizadas no documentário Gassman, Pasolini e i filologi, dirigido por Monica Centanni e Margherita Rubino, de 2005. Há uma fala aí do próprio Pasolini, que explica as "razões técnico-linguísticas" de suas escolhas tradutórias. Tendo em vista que ele não pretendia realizar nem uma "tradução literal", nem fazer uma "imediação classicista", o que faz é uma "tradução por analogia". Na sequência, explica o que entende por "tradução por analogia" fornecendo uma comparação:

Como eu fiz com o Evangelho, não reconstruí o ambiente arqueologicamente, filologicamente, mas o reconstruí por analogia, ou seja, uma vila, uma cidadezinha, um castelo da antiga Palestina substituído por uma vila, uma cidadezinha, um castelo do hodierno sul da Itália, que são semelhantes por analogia. ${ }^{7}$

Esta fala de Pasolini parece indicar uma possível solução entre a "estrangeirização" ou a "domesticação" do texto traduzido, ou seja, a antiga dicotomia já apontada por Schleiermacher entre levar o texto até os leitores ou levar os leitores até o texto. Pasolini, portanto, escolhe uma via intermediária, acrescentando, quando possível,

nortear a versão de Bocage é a fluência, vale dizer, o ritmo". É de se notar que nem o ritmo das traduções de Pasolini foi levado em consideração por Condello, que limitou sua análise às escolhas lexicais do poeta-tradutor.

6 " $[\ldots]$ ci sono punti in cui il traduttore rende il testo latino con parole o nessi che fanno parte del suo universo poético".

${ }^{7}$ Transcrição feita diretamente do vídeo (entre os minutos 3' e 4').

Cad. Trad., Florianópolis, v. 39, no 3, p. 209-229, set-dez, 2019. 
referências atuais, sem incorrer, aparentemente, em anacronismo ${ }^{8}$. No caso da peça Miles gloriosus, o poeta afirma: "Eu fiz uma tradução livre de Plauto, é verdade: mas livre em sentido estilístico, no interior do estilo" (Il Vantone di Plauto 156) ${ }^{9}$. Ao mesmo tempo, Pasolini sublinha uma das características marcantes de Plauto, o seu "antimilitarismo", e é aqui que lhe é permitido atualizar o texto romano, inserindo na boca do escravo um lema fascista: "vencer sempre vencer", que segundo o tradutor é "um mote que não pode estar privado de alusão direta para os italianos" $(157)^{10}$.

Estas duas últimas citações foram retiradas do apêndice que Umberto Todini acrescentou na edição organizada por ele da tradução de Pasolini do Miles gloriosus, que contém dois textos, sendo o primeiro uma carta que o poeta-tradutor enviou ao jornal Unità, de onde foram tirados os trechos citados no parágrafo anterior; o segundo é a orelha da primeira edição da tradução, de 1963 , em que o poeta declara ter traduzido com um "olho armado com a lente deformante do artesão na ânsia de 'refazimento', mais do que a lente do analista!" (Il Vantone di Plauto 157) ${ }^{11}$. Note-se que Pasolini não diz que seu trabalho é de tradução, pensada em termos acadêmicos, que não raro enrijecem o texto de chegada; diz, antes, que seu trabalho é de "refazedor", vocábulo que parece se aproximar da ideia de "recriação" proposta por Haroldo de Campos.

É neste sentido que Massimo Fusillo, em La Grecia secondo Pasolini, entende a tradução da Oresteia, ao contrário do professor Degani, que esquece "que esta tradução certamente não pretendia ser um exercício filológico, mas uma reelaboração poética,

\footnotetext{
${ }^{8}$ Paulo H. Britto afirma que, "na prática, o que sempre fazemos é exatamente aquilo que Schleiermacher diz ser impossível fazer: adotar posições intermediárias entre os dois extremos" (62).

9 "Io ho liberamente tradotto Plauto, è vero: ma liberamente in senso stilistico, all'interno dello stile".

10 "[...] un motto che non può essere privo di diretta allusività per gli italiani".

11 “[...] un occhio però armato della lente deformante dell'artigiano in smania di 'rifacimento', più che della lente dell'analista!"
}

Cad. Trad., Florianópolis, v. 39, no 3, p. 209-229, set-dez, 2019. 
e que sobretudo era destinada a uma representação teatral [...]" (Fusillo 192) ${ }^{12}$.

Este é outro elemento muito importante quando se trata de tradução de peça teatral, o que leva Fusillo a afirmar (194-5):

Justamente para não perder o impacto comunicativo com o público, aumentam neste caso as adaptações, as naturalizações, as modernizações: é, enfim, um âmbito em que os tradutores tendem mais a aproximar o texto ao leitor que vice-versa, segundo a dicotomia traçada por Schleiermacher. Pode-se observar isso já nas primeiras traduções teatrais que conhecemos, as reelaborações das comédias de Menandro por obra dos comediógrafos latinos. Pasolini, aliás, fez uma experiência neste campo, traduzindo o Miles gloriosus de Plauto em dialeto romanesco (Il vantone): o uso do dialeto é, de fato, uma forma radical de naturalização do modelo. ${ }^{13}$

Além disso, Fusillo detectou que os elementos mitológicos são "transformados segundo a poética pasoliniana da religiosidade quotidiana: a suma divindade da mitologia grega, Zeus, é sempre traduzido como 'Deus', assim como os 'templos' se tornam 'igrejas', enquanto na procissão final aparece o 'hosana' [...]” (195) $)^{14}$. Esta

12 " [...] che questa traduzione non voleva certo essere un esercizio filologico, ma una rielaborazione poetica, e che soprattutto era finalizzata a una rappresentazione teatrale $[\ldots] "$.

13 "Proprio per non perdere l'impatto comunicativo con il pubblico, aumentano in questo caso gli adattamenti, le naturalizzazioni, le modernizzazioni: è insomma un ambito in cui i traduttori tendono di più ad avvicinare il testo al lettore che viceversa, secondo la dicotomia tracciata da Schleiermacher. Lo si può osservare giè nelle prime traduzioni teatrali che conosciamo, i rifacimenti delle commedia di Menandro ad opera dei commediografi latini. Pasolini fece fra l'altro un'esperienza in questo campo, traducendo il Miles gloriosus di Plauto in dialetto romanesco (Il vantone): l'uso del dialetto è infatti una forma radicale di naturalizzazione del modello".

14 "[...] trasformati secondo la poetica pasoliniana della religiosità contadina: la divinità somma della mitologia greca, Zeus, viene sempre tradotto come 'Dio', 
parece ser uma tendência das traduções de Pasolini, como veremos em algumas escolhas tradutórias para verter a Eneida ao italiano.

No texto que apresentamos nos limitaremos a uma breve história da tradução dos primeiros 300 versos da Eneida de Virgílio, assim como uma breve análise de algumas das escolhas que Pasolini fez ao traduzi-los.

Antes de tudo, deve-se levar em conta que ainda hoje os críticos não afirmam com certeza se Pasolini traduziu apenas estes 300 versos, conforme aponta Umberto Todini $(49)^{15}$. Também não se sabe ao certo quando ele teria realizado a tradução nem o motivo que o teria levado a esta empreitada. Em uma entrevista de 25 de maio de 1959, que tratava de um novo romance de Pasolini, concedida a Adolfo Chiesa, lemos a descrição do entrevistador ao chegar à casa do poeta (qdt. in Todini 49):

Olhamos a mesa em que o escritor trabalha, apinhada de papéis, livros, como uma alta trincheira. Uma surpresa nos aguarda: o poeta começou uma empreitada de grande fôlego, a tradução da Eneida em versos, uma empreitada certamente de empenho, mas que Pasolini considera extraordinariamente "relaxante". Seus olhos brilham ao falar dela. E acrescenta coisas muito interessantes sobre as dificuldades de traduzir: 'Homero, diz, eu não poderia enfrentá-lo; a empreitada hoje é impossível. Homero é poeta demais, genuinamente poeta; e nestes nossos tempos pode-se procurar refazer uma maneira, uma retórica. Um tradutor não seria capaz de transpôr uma expressão autêntica, popular, como é a poesia homérica; mas pode penetrar aquelas obras que obedecem a uma poética' ${ }^{16}$

così come i 'templi' diventano 'chiese', mentre nella processione finale compare l'osana' [...].

${ }^{15}$ Agradeço ao prof. Rino Caputo, da Università di Roma Tor Vergata, por ter me fornecido este texto, indisponível no Brasil.

16 "Guardiamo sul tavolo su cui lo scrittore lavora, stipato di carte, di libri, come un'alta trincea. Qui una sopresa ci attende: il poeta si è accinto infatti ad un'impresa di gran lena, e cioè la traduzione dell'Eneide in versi, un'impresa

Cad. Trad., Florianópolis, v. 39, nº 3, p. 209-229, set-dez, 2019. 
Parece, então, que o poeta havia pensado em traduzir Homero, mas na falta de uma linguagem popular, autêntica, esta tarefa não era possível, ao passo que Virgílio, por ser um poeta que obedece a uma poética, seria possível traduzir. Esta informação, além disto, pode dar a entender que o projeto de Pasolini seria traduzir a Enei$d a$ toda. Se este projeto foi levado a cabo, não temos como saber, e se foi concluído, tanto pior, pois então significa que está esquecido em algum canto, mas isto nos parece pouco provável.

O material produzido pelo poeta encontra-se no Archivio Pasolini, onde há o registro da tradução da Eneida contendo três redações, mais uma prova de seu interesse nesta tradução. A primeira redação, em folhas pequenas formato caderno, mostra muitas correções, geralmente limitadas ao léxico e a breves trechos do texto que raramente tocam a sintaxe. Na última página do caderno há várias tentativas de tradução para o incipit do poema, e isto, evidentemente, é visível no texto publicado.

As segunda e terceira versões seguem praticamente as correções feitas à primeira versão, sendo que uma das duas cópias apresenta outras correções ainda, e este é o texto com o qual trabalhamos, incluído nas poesias completas da coleção "I Meridiani” da editora Mondadori ( $1^{\mathrm{a}}$ ed. 2003).

Já vimos que na entrevista concedida a Adolfo Chiesa do jornal Paese sera, o poeta declara que havia iniciado a tradução da Enei$d a$; mas Todini, estudioso de Pasolini imprescindível para analisar esta tradução, traz uma lembrança pessoal de Andrea Zanzotto que falava de um projeto de traduzir "a várias mãos" a Eneida, a partir de uma proposta do editor Neri Pozza, poucos anos antes de 1959, sendo que cada poeta deveria se dedicar a um canto.

certamente d'impegno, ma che Pasolini considera straordinariamente 'distensiva'. Gli occhi gli si illuminano nel parlarne. E, anzi, aggiunge cose molto interessanti per la sua fatica di traduttore: 'Omero, egli dice, non avrei potuto affrontarlo; l'impresa oggi è impossibile. Omero è troppo poeta, genuinamente poeta; e in questi nostri tempi si può cercare di rifare una maniera, una rettorica. A un traduttore non riuscirebbe rendere un'espressione autentica, popolare, quale è la poesia omerica; ma può invece penetrare quelle opere che obbediscono a una poetica'".

Cad. Trad., Florianópolis, v. 39, no 3, p. 209-229, set-dez, 2019. 
Zanzotto chegou a publicar as suas traduções da Eneida numa antologia escolar organizada por Giacinto Spagnoletti, em 1962. Mas será que teria cabido a Pasolini justamente o primeiro canto da Eneida? Além disto, naquele mesmo período, Zanzotto lembra que ele próprio, Mario Luzi e Pasolini tinham se envolvido numa outra empreitada coletiva (também não levada a cabo): a tradução das cartas do apóstolo Paulo. Pasolini, sempre segundo Zanzotto, teria traduzido a Epístola aos Romanos. Anos mais tarde, esta tradução serviu de núcleo para uma encenação, nunca realizada e publicada postumamente, intitulada San Paolo (Zanzotto). Um trabalho, de acordo com Todini, que traz sinais evidentes de uma relação direta com o texto latino, além de revelar profundas leituras de psicanálise.

Mas voltando a Virgílio, o mais provável é que Pasolini não tenha concluído a tradução da Eneida, mesmo porque naqueles anos realizou inúmeros outros trabalhos, como a tradução da Oresteia de Ésquilo (1960) e do Miles gloriosus de Plauto (1963), sem contar a publicação de obras suas: Uma vida violenta, de 1959; A religião do meu tempo, de 1961, mesmo ano em que começa a filmar Accattone; $O$ sonho de uma coisa, de 1962, mesmo ano do longa Mamma Roma . Outro motivo que poderia ter levado Pasolini a abandonar essa empreitada é que em 1962 surgiram duas traduções completas da Eneida, uma de Rosa Calzecchi Onesti (tradutora também da Ilíada e da Odisseia), pela então renomada editora Einaudi, e outra de Cesare Vivaldi (tradutor também de Marcial, Juvenal entre outros), por outra editora não menos importante, Guanda.

Ainda antes de entrarmos na tradução, convém relembrar outras palavras de Pasolini sobre tradução. No jornal Il Punto, em 8 de dezembro de 1956, com o título "Arte e divulgação", ele escreve (Saggi sulla letteratura e sull'arte 659, grifos nossos):

A ideia mais corrente que se tem da tradução é que se trate de um ato absolutamente aproximativo: ou melhor, que se trate de uma redução: mercadoria não apenas secundária, mas diminuída por um improvisado surgir, causado pela sua própria presença, ainda que discreta, do grande fantasma do inefável. 
Geralmente, o que justifica uma tradução é o fim informativo. [...]

Mas existe um segundo modo de tradução: no qual, à função de divulgar - às vezes encomendada - se acrescenta a intenção de fazer, ou, melhor, de refazer, poesia. No limite mais alto, tal intenção se concretiza tout court em assimilar o texto traduzido à linguagem do tradutor sendo ele próprio poeta: uma espécie de regeneração (exemplos típicos: o Homero de Monti, os românticos de Carducci, os gregos de Quasimodo). ${ }^{17}$

Vemos aí explicitamente a continuação da ideia que apresentamos mais acima, a saber, que Pasolini julgava imprescindível ao tradutor que fosse também poeta "assimilar o texto traduzido" à sua linguagem, ou seja, à sua poética. Mais adiante, neste mesmo artigo, Pasolini afirma que há dois tipos principais de tradução, um "prático" e outro "artístico", o primeiro representado, no melhor dos casos, por um acadêmico, e o segundo, por um poeta. Ao comparar estes dois tipos de tradução, Pasolini ressalta (Saggi sulla letteratura e sull'arte 660):

[...] uma segunda característica comum aos dois tipos de tradução aqui, na nossa nota, é importante. Trata-se de uma evidente necessidade - no primeiro caso óbvia, no segundo reveladora - de espírito filológico: que o universitário

17 "L'idea più corrente che si ha della traduzione è che si tratti di un atto assolutamente approssimativo: che si tratti, piuttosto, di una riduzione: merce non solo secondaria, ma menomata da un improvviso insorgere, causato dalla sua stessa presenza, sia pur discreta, del grande fantasma dell'ineffabile.

In genere ciò che giustifica una traduzione è il fine informativo. [...]

Ma esiste un secondo modo di tradurre: in cui, alla funzione del divulgare talvolta commissionata - si aggiunge l'intenzione di fare, o, meglio, di rifare, poesia. Al limite alto tale intenzione si concreta tout court in una assunzione del testo tradotto al linguaggio del traduttore in quanto egli stesso poeta: una specie di rigenerazione (esempi tipici: l'Omero di Monti, i romantici di Carducci, i greci di Quasimodo)". 
resolverá com notas no seu "texto bilíngue", com interpolações prosásticas na módica dignidade literária do próprio texto: mas que o poeta resolverá intuitivamente (talvez, se se trata de um poeta do século 20 , com puro processo fonético) através de uma invenção "vivaz" do vocábulo em que se coágula todo um complicado desenrolar semântico.

Tudo isto põe em evidência o fato que a tradução é sobretudo, explícita ou implicitamente, um ato historiográfico. ${ }^{18}$

Sendo Pasolini um poeta do século 20, como ele resolveu a "necessidade de espírito filológico"? E mais, sendo um poeta que traduzia para mais de uma língua (friulano, romanesco, italiano), qual língua iria ele adotar na tradução da Eneida? No apêndice à tradução da Oresteia, Pasolini comenta: "Como traduzir? Eu já possuía um 'italiano': e era naturalmente o das Cinzas de Gramsci (com algum toque expressivo de $O$ rouxinol da igreja católica); eu sabia (por instinto) que poderia fazer uso dele" (Teatro 1008) ${ }^{19}$.

Parece que foi justamente este mesmo italiano que Pasolini usou para traduzir a Eneida de Virgílio. O poeta optou ainda por versos livres, além de ter usado de grande liberdade na escolha do léxico e da sintaxe. Já notaram os organizadores das poesias completas da edição mondadoriana que "O seu modo de traduzir é extremamente livre, jamais ligado ao pé da letra” (Tutte le poesie 1784) ${ }^{20}$.

18 " [...] una seconda caratteristica comune ai due tipi di traduzione qui, nel nostro appunto, importa. Si tratta di una evidente necessità - nel primo caso ovvia, nel secondo rivelatrice - di spirito filologico: che l'universitario assolverà in note al suo 'testo a fronte', in interpolazioni prosastiche alla modica dignità letteraria del testo stesso: ma che il poeta assolverà intuitivamente (magari, se si tratta di un poeta del Novecento, con puro processo fonetico) attraverso una invenzione 'vivace' del vocabolo in cui si coagula tutta una complicata vicenda semantica.

Tutto questo mette in evidenza il fatto che la tradizione è soprattutto, esplicitamente o implicitamente, un atto storiografico".

19 “Come tradurre? Io possedevo già un 'italiano': ed era naturalmente quello delle Ceneri di Gramsci (con qualche punta espressiva sopravvissuta da L'usignolo della Chiesa Cattolica); sapevo (per istinto) che avrei potuto farne uso".

20 "Il suo modo di tradurre è estremamente libero, mai legato alla resa letterale".

Cad. Trad., Florianópolis, v. 39, nº 3, p. 209-229, set-dez, 2019. 
Exemplos dessa liberdade na tradução são muitos, como a escolha de "religione" para "deos" (v. 6), ou "emigrati" para "coloni" (v. 12), ilustrando a atualização que Pasolini do texto antigo. Em outros momentos, contudo, notamos que Pasolini opta por simplificar, ajudar o leitor com a tradução, como no caso dos nomes próprios: "Ilium" (v. 68) por "Troia"; "Iliacis" (v. 97) por "troiani"; "Teucri" (v. 235) por "di Troia"; "Achiuis" (v. 242) por "Greci"; "gente sub Hectora" (v. 273) por "razza troiana"; "Argis" (v. 285) por "Greci".

Há outros exemplos de "facilitação" do texto, seja através da inserção do sujeito (que no original estava elíptico): "Enea si ferma" para o constitit do verso 187; "Enea" para o "heros" do verso 196; ou "Enea (te lo dico)" para o simples "tibi" do verso 261. Um caso muito relevante é a omissão do epíteto que acompanha o herói da Eneida, o pius Aeneas, ou seja, o "devoto Eneias", que Pasolini não traduz: v. 220: pius Aeneas = "Enea". Uma explicação possível seria que, sabendo que o significado principal do epíteto na épica antiga era o de designar uma espécie de arquétipo da personagem, Pasolini optou por excluir esse tipo de fatalismo da poesia arcaica, dando mais flexibilidade ao seu personagem, situado no século 20, como fez com a tradução de fato por "storia", que comentaremos a seguir.

Considerando os 11 primeiros versos da Eneida como seu exórdio, vale a pena incluir aqui o original e a tradução de Pasolini (Tutte le poesie 1333):

Arma uirumque cano, Troiae qui primus ab oris Italiam fato profugus Lauiniaque uenit litora, multum ille et terris iactatus et alto ui superum, saeuae memorem Iunonis ob iram,

5 multa quoque et bello passus, dum conderet urbem inferretque deos Latio, genus unde Latinum Albanique patres atque altae moenia Romae. Musa, mihi causas memora, quo numine laeso quidue dolens regina deum tot uoluere casus 
10 insignem pietate uirum, tot adires labores impulerit. Tantaene animis caelestibus irae? ${ }^{21}$

Canto la lotta di un uomo, che, profugo da Troia, la storia spinse per primo alle sponde del Lazio: la violenza celeste, e il rancore di una dea nemica, lo trascinarono da un mare all'altro, da una terra

5 all'altra, di guerra in guerra, prima di fondare la sua città e di portare nel Lazio la sua religione: origine del popolo latino, e albano, e della suprema Roma. $\mathrm{Tu}$, spirito, esponi le intime cause: per quale offesa, o per quale dolore, la regina degli dei obbligò quell'uomo

10 così religioso, a dover affrontare tanti casi, tante fatiche: miseria di passioni nei cuori celesti!

Em primeiro lugar, percebe-se que Pasolini optou por versos livres e não seguiu nenhum esquema rígido. Em segundo lugar, temos aí dois exemplos de escolha lexical que mais despertam nossa atenção: a tradução de $M u s a$ do v. 8 por "spirito", já notado por Todini, segundo o qual se trata do fundamento literário e religioso da cultura antiga, do epos virgiliano, que é traduzido por "espírito", talvez com alguma reminiscência do animus de Ovídio no início das Metamorfoses. Isto parece indicar que Pasolini se aproximaria mais da ideia de um ânimo histórico que compõe o poema, e não uma entidade divina, neste caso, a Musa.

Outra escolha surpreendente é a tradução de fato do v. 2 por "storia”. Não mais o destino, mas a história. Este é um caso em que precisamos ampliar nosso olhar para atingir a poética de Pasolini. Se pensamos, por exemplo, no poema $O$ pranto da escavadora, que é de 1956, pouco anterior à tradução da Eneida, percebemos que a invenção moderna da escavadora não é um destino, mas parte da história, que ela representa de modo material e simbólico, em particular na sua intromissão na paisagem romana pondo-a em risco, uma

${ }^{21}$ Texto da edição de J. Perret (Les Belles Lettres). 
geografia ameaçada pelo desenvolvimento industrial e pela crescente homogeneização cultural. Assim, para Pasolini não existe mais o destino, e sim a história ${ }^{22}$. No entanto, em outros momentos em que aparece o mesmo termo fatum, Pasolini o traduz por "destino" (versos 39, 222, 239 e 258). Isto nos remete ao fato de que Pasolini fez várias tentativas justamente para o incipit, onde o substantivo fatum é traduzido por "storia" nas suas duas primeiras aparições (v. 2 e v. 18), enquanto no resto da tradução aparece como "destino".

A solução para o substantivo pietas do verso 10 traduzido pelo adjetivo "religioso" nos parece pertinente. Se por um lado Pasolini não traduz o epíteto de Eneias, por motivos vistos acima, por outro, aqui traduz um dos elementos centrais da Eneida: a devoção de Eneias. De fato, há quem leia no adjetivo "pius" e seus derivados a acepção de quem cumpre com os ritos religiosos, sem mesmo questionar as divindades, como é o caso de Eneias, que sequer pensa duas vezes antes de abandonar Dido.

Notamos aí também, quanto ao léxico, a facilitação no verso 2, "sponde del Lazio", pelo original "Lauiniaque [...] litora", que forma um enjambement entre os versos 2 e 3 (efeito eliminado por Pasolini). Uma perda relevante aqui diz respeito ao adjetivo "Lauinia", no neutro plural concordando com o substantivo "litora" 23 . É possível ler este adjetivo, como propõe Conington (4), como uma antecipação do nome da cidade que será fundada por Eneias. Além disso, parece-nos que é como se o narrador já adiantasse o nome da filha do rei Latino, prometida em casamento a Turno, mas dada

${ }^{22}$ P. Lago interpreta da seguinte forma a escolha de Pasolini: "No lugar de destino, do fado, Pasolini usa um elemento racional como a história; é a história, entendida como contexto sócio-político, como universo lógico que encerra os destinos dos seres humanos, a determinar as peregrinações de Eneias, não o destino" (26-27). ${ }^{23}$ Há variação de ortografia quanto a esse adjetivo. Nas edições críticas de Ettore Paratore (coleção Fondazione Lorenzo Valla), de H. Rushton Fairclough (coleção Loeb) e de Fredericus A. Hirtzel (coleção Scriptorum classicorum bibliotheca oxoniensis) vem grafado Lavinaque, enquanto a edição, também crítica, de Jacques Perret (coleção Les Belles Lettres) opta por Lauiniaque. Para o nosso argumento, a variação tem pouca importância. Para uma breve discussão a respeito das duas grafias, ver o comentário de Paratore na sua edição (128).

Cad. Trad., Florianópolis, v. 39, no 3, p. 209-229, set-dez, 2019. 
a Eneias, e que será o motivo da batalha entre esses dois heróis da epopeia. Assim, ao traduzir "Lauinia [...] litora" por "sponde del Lazio", Pasolini ganha na agilidade do verso, mas perde nas possíveis referências que o nome oferece.

Se o enjambement dos versos 2 e 3 foi excluído, Pasolini fez questão de incluí-lo entre os versos 4 e 5, importante por reforçar a ideia sugerida pelo texto, segundo o qual o herói havia sido lançado de um lado para outro, prova de seus infortúnios. No entanto, o tradutor inverteu a sequência dos versos 3 e 4 talvez para facilitar sua leitura, pois acrescentou um verbo no pretérito do indicativo ("trascinarono") para traduzir os dois particípios passados do original, iactatus e passus, e deu como sujeito o agente vi superum e a locução $o b$ iram. Assim, a leitura fica mais corrente com os sujeitos "la violenza celeste, e il rancore" prepostos ao verbo que se encontra no verso seguinte. Uma perda aqui é a não tradução do nome de Juno, deusa adversária dos troianos, compensada, porém, com o adjetivo "nemica".

Há também um exemplo de acréscimo por parte do tradutor que só pode ser entendido se levarmos em conta o universo de Pasolini. No verso 8, o narrador interpela a Musa, ordenando que relembre as causas das desventuras de Eneias. O tradutor, porém, inclui o adjetivo "intime cause": é como se não bastasse recordar as causas, que podem ser vagas, burocráticas, mas os verdadeiros motivos, íntimos, que levaram esse varão tão insigne por sua devoção a sofrer tantos males. O resultado, ao que nos parece, é que a história do personagem ganha em profundidade.

Quanto à sintaxe, chama a atenção a junção, por parte do tradutor, dos dois substantivos do original que definem a matéria a ser cantada e que remetem, desde a abertura do poema, aos dois principais modelos seguidos por Virgílio, a Ilíada e a Odisseia, respectivamente assinaladas por arma e uirum. Pasolini, porém, registra como complemento objeto direto do verbo cantar apenas o substantivo "lotta", substituindo a conjunção aditiva "e" por um genitivo (adjunto adnominal restritivo), "di un uomo". Pensando que a tradução é um jogo de vantagens e desvantagens, perdas e 
ganhos, Pasolini aqui perde a força que o texto original oferece, mas ganha em sentido de atualização do texto paralelamente à sua poética; assim, "canto la lotta di un uomo" parece transformar o caráter específico da representação daquele herói da antiguidade, Eneias, em uma ideia que torne possível a qualquer um se identificar com ela, como se fosse a luta de cada um, ou seja, Pasolini historiciza o protagonista da Eneida.

Um último aspecto a ser levado em conta diz respeito aos períodos do original, que nas edições modernas vêm marcados pela pontuação, e que são, na maioria das vezes, seguidos por Pasolini. É digna de nota sua escolha em alterar uma frase interrogativa (no original introduzida pelo "ne" enclítico, ou seja, mesmo sem a pontuação moderna a presença da partícula interrogativa marca a pergunta com nuance de "acaso", "por ventura") para uma exclamativa afirmativa:

\section{Tantaene animis caelestibus irae?}

miseria di passioni nei cuori celesti!

Uma tradução literal seria algo como: "Por acaso é tão grande a ira nos espíritos celestiais?". Na versão de Pasolini, contudo, é como se o poeta do século 20 não tivesse mais dúvida quanto às "paixões" dos deuses, por isso não se interroga sobre uma possível ira dos celestiais, ao contrário, afirma o aspecto humano deles. Note-se ainda a tradução de irae por "passioni”; por um lado, há a perda de uma possível alusão à ira de Aquiles (que, por extensão, pode funcionar como referência à Ilíada como um todo) em posição de destaque no verso, que parece retomar o quarto verso, que também contém ira como última palavra e se refere à Juno; por outro, parece que Pasolini humaniza os deuses ao atribuir-lhes um sentimento que, ao menos na antiguidade, não era normalmente conferido a eles, ao passo que a ira sim. 
Podemos concluir que Pasolini, então, opta por uma via intermediária entre a "domesticação" e a "estrangeirização", pois, ao mesmo tempo que traz Virgílio ao leitor contemporâneo ao usar um léxico e uma sintaxe correntes da língua italiana do século 20, talvez um italiano das Cinzas de Gramsci ou dos romances daqueles anos ( $O$ sonho de uma coisa e Uma vida violenta, este último nas partes do narrador, e não nas partes dialogadas, que retomam o romanesco), introduz termos que são próprios da sua poética, como no caso da tradução de "destino" por "história".

\section{Referências}

Bertolucci, Attilio. Poesia straniera del Novecento. Milão, Garzanti, 1958.

Britto, Paulo Henriques. A tradução literária. Rio de Janeiro: Civilização brasileira, 2016.

Gassman, Pasolini e i filologi. Dir. Monica Centanni, and Margherita Rubino. [La Rivista di] Engramma, 2005. Documentary.

Condello, Federico. "Su Pasolini traduttore classico: rilievi sparsi, tra fatto e legende”. Semicerchio: rivista di poesia comparata 47.2 (2012): 8-17.

Fusillo, Massimo. La Grecia secondo Pasolini: mito e cinema. Florença: La Nuova Italia, 1996.

Lago, Paolo. "Un logos antiaccademico: Pasolini traduttore dell'Eneide". Semicerchio: rivista di poesia comparata 46.2 (2012): 23-30. 
Moraes, Vinicius de. Obra poética. Rio de Janeiro: José Aguilar, 1968.

Mounin, Georges. Teoria e storia della traduzione. Trad. Stefania Morganti. Turim: Einaudi, 2006.

Ovídio. Metamorfoses. Trad. Bocage. Introd. João Angelo Oliva Neto. São Paulo: Hedra, 2007.

Pasolini, Pier Paolo. Il sogno di una cosa. Milão: Garzanti, 1962.

Pasolini, Pier Paolo. Il Vantone di Plauto. Ed. U. Todini. Milão: Garzanti, 2008.

Pasolini, Pier Paolo. Saggi sulla letteratura e sull'arte. Ed. W. Siti and S. De Laude. Milão: Mondadori, 2008.

Pasolini, Pier Paolo. Teatro. Ed. W. Siti e S. De Laude. Milão: Mondadori, 2001.

Pasolini, Pier Paolo. Tutte le poesie. Ed. W. Siti. Milão: Mondadori, 2009.

Pasolini, Pier Paolo. Una vita violenta. Milão: Garzanti, 1959.

Todini, Umberto. "Virgilio e Plauto, Pasolini e Zanzotto. Ineditti e manoscritti d'autore tra antico e moderno". Lezioni su Pasolini. Ascoli Piceno: Sestante, 1997.

Virgílio. Eneide. Trad. Cesare Vivaldi. Parma: Guanda, 1962.

Virgílio. Énéide. Ed. e trad. J. Perret. Paris: Les Belles Lettres, 1977.

Virgílio. Eneide. Ed. E. Paratore. Trad. L. Canali. Vol. I. [S.1.]: Fondazione Lorenzo Valla; Arnoldo Mondadori Editore, 2012.

Virgílio. L'Eneide. Ed. e trad. Rosa Calzecchi Onesti. Milão: Einaudi, 1962. 
Virgílio. P. Vergili Maronis Opera. Ed. J. Conington. Vol. II. Londres: Whittaker \& Co., 1884.

Zanzotto, Andrea. San Paolo. Turim: Einaudi, 1977.

Recebido em: 20/04/2019

Aceito em: 10/07/2019

Publicado em: Setembro de 2019

Pedro Falleiros Heise. Email: pedraofh@yahoo.com ORCID: 0000-0001-6640-6992. 